\title{
Purification of HRSV F protein from a eukaryotic expression vector and establishment of a sandwich ELISA method
}

\author{
HONG BAO, TING YU, YUFEN JIN, CHUNE WANG and YANLEI LI \\ The Second Hospital of Jilin University, Changchun, Jilin 130041, P.R. China
}

Received December 31, 2011; Accepted February 15, 2012

DOI: $10.3892 / \mathrm{mmr} .2012 .872$

\begin{abstract}
In order to increase the expression of the fusion (F) protein and lay a foundation for the construction of a genetically engineered vaccine and rapid clinical detection, the F protein of the human respiratory syncytial virus (HRSV) was expressed and purified, and a sandwich enzyme-linked immunosorbent assay (ELISA) method was established. The F1 fragment of the HRSV F protein was amplified following reverse transcription, and was then combined with the vector and transformed into eukaryotic cells. The recombinant protein was induced and purified. The purified protein was used to immunize mice to produce antiserum and establish indirect ELISA. The established method was tested and verified by analyzing 100 samples using gold immunochromatography (GICA). The F1 fragment of the F gene was successfully amplified, the DNA (+) recombinant was selected, and a protein of molecular weight approximately 45,000 was obtained after the induction. The optimal reaction conditions and working concentration of ELISA were determined. The optimal concentration of mice anti-F1 IgG is $3.2 \mu \mathrm{g} / \mathrm{ml}$, the best reaction time of the samples is $70 \mathrm{~min}$ at $37^{\circ} \mathrm{C}$, and the working concentration of the rabbit anti-mouse $\operatorname{IgG}$ is $1: 6,000$. Compared with the GICA method, the sample's positive co-efficient of variation was $3.2-8.6 \%$, and the negative co-efficient of variation was $5.1-8.3 \%$. These were $<10 \%$, indicating that the ELISA method was reproducible. The F1 protein can be greatly expressed in transfected eukaryotic cells, and the purified F1 protein has good immunogenicity. The antiserum produced by the purified recombinant protein can be precisely detected using the ELISA detection method described in this study.
\end{abstract}

\section{Introduction}

Human respiratory syncytial virus (HRSV) is one of the main causes of serious lower respiratory tract infections in infants, young children, the elderly and immunocompromised

Correspondence to: Dr Ting Yu, The Second Hospital of Jilin University, Changchun, Jilin 130041, P.R. China

E-mail: yuting485@163.com

Key words: human respiratory syncytial virus, recombinant protein, indirect ELISA patients (1), and is the main cause of infant hospitalization. As antibodies produced by primary HRSV infection in the body do not provide permanent protection, the WHO demands the strict monitoring of HRSV. HRSV infection outbreaks are generally sporadic; however, a number of large-scale epidemics have been noted in China, showing that there are geographic and epidemiological parameters involved. The main epidemic type of HRSV in China is subtype A.

HRSV is a member of the paramyxovirus family of the pneumovirus genus, and is a non-segmented, single-stranded negative-sense RNA virus. It encodes ten major proteins, including the membrane fusion $(\mathrm{F})$ protein and the adhesion protein $\mathrm{G}$. These two proteins are the most important viral antigens that stimulate the body to produce protective antibodies (2). The F protein mediates fusion between the virus and cells, virus penetration and syncytia formation. Neutralizing antibodies induced by the F protein can simultaneously inhibit virus infection caused by subtypes $\mathrm{A}$ and $\mathrm{B}$. Between the same subtypes or different subtypes of the local strain, there is a highly homologous antigen; antigen correlation between the different subtypes is approximately 53\%, homology of the amino acid sequence is approximately $89 \%$. The $\mathrm{F}$ protein is a major cross-protective antigen, which provides a significant basis for HRSV vaccine research (3).

The F protein is a typical type I glycoprotein. It was initially translated into a non-active precursor type $\mathrm{F} 0$ with a relative molecular weight of 70,000. F0 can be cut into F1 and F2 subunits by an endogenous tyrosine-like protease. The main epitope of the $\mathrm{F}$ protein is concentrated on the $\mathrm{F} 1$ region; this peptide section has the immunogenicity. The $\mathrm{F} 1$ region of the F protein in the HRSV type A long-strain has been expressed in eukaryotic cells using genetic recombination, and the protein purification has been explored (4). The indirect sandwich enzyme-linked immunosorbent assay (ELISA) method was preliminarily established based on a specific fragment of the F protein, and was used for detecting serum HRSV. The successful expression of $F$ protein in eukaryotic cells has provided the basis for the further development of diagnostic kits and an HRSV vaccine.

\section{Materials and methods}

Materials. The COS27 cell line, the E. coli strain, DH5 $\alpha$, the pcDNA3.1 (+) vector and pShutter-CMV vector were retrieved from our laboratory. The pGEM-T-easy vector was 
obtained from Promega, the liposome transfection kit, the Lipofectamine 2000 from Invitrogen; T4 DNA ligase, Taq DNA polymerase, Pfu DNA polymerase and restriction enzymes from Takara, nitrocellulose membrane, and the Ni-protein purification column from Amersham.

The ELISA reagents consisted of fetal calf serum, trypsin (1:250; Gibco); Freund's complete adjuvant, Freund's incomplete adjuvant and bovine serum albumin (BSA; Sigma); horseradish-peroxidase (HRP) labeled rabbit anti-mouse antibody (Beijing Biosynthesis Biotechnology Co., Ltd.); coated wells (Costar), $\mathrm{CHT}^{\mathrm{TM}}$ ceramic hydroxyapatite and UNO-sphere ${ }^{\mathrm{TM}} \mathrm{Q}$ anion-exchange packing (Bio-Rad Inc.); respiratory syncytial virus antibodies ( $\operatorname{IgG} / \operatorname{IgM})$, gold immnnochromatography (GICA) kit (Shanghai Yeyuan Bio-Tech Co., Ltd.). A total of 100 samples from the Changchun Children's Hospital, Changchun, China were examined.

According to the BLAST results of the F protein gene sequence alignments in GenBank, the upstream and downstream primers were designed in the conserved region. The primers were synthesized by Shanghai Bio-Engineering Co., Ltd.; upstream primer, 5'-CGCGGATCCGGGGAAGTGAAC AAAAT-3'; downstream primer, 5'-CCCAAGCTTCTAGAAT ATGTCAACGTTGCAG-3'. BamHI and HindIII restriction sites were added to the upstream and downstream primers, respectively.

Cloning of F1-His gene sequence. The viral RNA was extracted using the TRIzol method. After adding $1 \mu \mathrm{l}$ virus RNA, $5 \mu \mathrm{l}$ 10X Pfu high-fidelity enzyme buffer, $5 \mu 12 \mathrm{mmol} / 1 \mathrm{dNTPs}$, $2 \mu \mathrm{l}$ upstream and downstream primers, $0.5 \mu \mathrm{l}$ Pfu high-fidelity TaqDNA polymerase enzymes and sterile double-distilled water were added at a total volume of $50 \mu \mathrm{l}$ and mixed well. The reverse transcription reaction conditions were $45 \mathrm{~min}$ at $42^{\circ} \mathrm{C}$ and $5 \mathrm{~min}$ at $95^{\circ} \mathrm{C}$. The $\mathrm{PCR}$ reaction conditions were $10 \mathrm{~min}$ at $94^{\circ} \mathrm{C}, 1 \mathrm{~min}$ at $94^{\circ} \mathrm{C}, 1 \mathrm{~min}$ at $45^{\circ} \mathrm{C}, 90 \mathrm{sec}$ at $72^{\circ} \mathrm{C}$, 40 cycles, $72^{\circ} \mathrm{C}$ for $10 \mathrm{~min}$.

Cloning and sequencing of the target gene. The purified PCR products were connected with the pGEM-T-easy vector, and then transformed into $E$. coli competent DH5 $\alpha$ cells. White colonies were selected through blue-white screening. The plasmid was extracted and digested using an EcoRI restriction enzyme. After sequence analysis, the plasmid was digested using double digestion with BamHI and HindIII. The F1-His fragment was retrieved and connected with the pShuttle-CMV vector digested by the same double digestion. Following transformation, the plates were coated and the bacteria were agitated, and a small amount of plasmid was extracted and digested using double digestion with NotI and XbaI. The F1-His fragment was retrieved and connected with the pcDNA3.1 (+) vector digested by the same double NotI and XbaI digestion. Following transformation, the plates were coated and the bacteria were agitated, and a small amount of plasmid was extracted and digested with $\mathrm{XhoI}$ and HindIII and identified. The recombinant plasmid was named pcDNA3.1 (+)/F1-His.

Transient transfection. A large amount of plasmid pcDNA3.1 (+)/ F1-His was extracted and purified. The plasmid concentration was adjusted to $250 \mathrm{ng} / \mu \mathrm{l}$. The COS27 cells were cultured in Dulbecco's modified Eagle's medium (DMEM) until cell confluence reached $80-90 \%$ in the T-75 bottle. Transfection was conducted using liposome Lipofectamine 2000 according to the manufacturer's instructions.

Ni-purified protein and western blot analysis. Protein supernatant $(200 \mu \mathrm{l})$ was harvested after 72-h transfection and purified according to kit instructions. The protein in the elution peak was collected, and then analyzed by SDS-PAGE gel electrophoresis.

The target protein was transferred onto a nitrocellulose (NC) membrane. The NC membrane was blocked with PBS containing $50 \mathrm{~g} / \mathrm{l}$ skimmed milk at $4^{\circ} \mathrm{C}$ overnight, and was then washed three times with PBS. The positive serum was diluted to $1: 20$ with blocking solution, and was incubated with NC membranes at $37^{\circ} \mathrm{C}$ for $2 \mathrm{~h}$. After the membrane was washed three times with PBS, HRP-labeled goat anti-human IgG was added and incubated at $37^{\circ} \mathrm{C}$ for $1 \mathrm{~h}$. After the membrane was washed with PBS, the protein was revealed using DAB.

Establishment of indirect sandwich ELISA. Female mice (6 to 8 weeks old) were selected and randomly divided into four groups $(\mathrm{n}=5)$; the $\mathrm{F} 1+\mathrm{Al}(\mathrm{OH})_{3}$ group, the $\mathrm{F} 1$ protein group, the $\mathrm{Al}(\mathrm{OH})_{3}$ group and the PBS group. Recombinant proteins $(0.1 \mu \mathrm{g} / \mathrm{ml})$ were injected into the mice quadriceps and $\mathrm{Al}(\mathrm{OH})_{3}$ was used as the adjuvant (final concentration, $1.2 \mathrm{mg} / \mathrm{ml}$ ). The mice in the $\mathrm{F} 1$ protein group were injected with $0.1 \mu \mathrm{g} / \mathrm{ml}$ recombinant protein and $200 \mu \mathrm{l} \mathrm{Al}(\mathrm{OH})_{3}$. The mice in the negative control group were injected with PBS. This process was repeated three times every 14 days to strengthen immunization. Ten days after the last immunization, blood serum was collected from the orbital plexus, and the spleens were removed for spleen single cell suspension. The ELISA plates were coated with diluted purified $\mathrm{F} 1$ recombinant protein $(0.25 \mu \mathrm{g}$ for each well). Mouse antibody serum at a dilution of 1:320 was added to the first well, and a series of diluted sera were added to other wells. The secondary antibody was goat anti-mouse IgG-HRP at 1:2,000 dilution. Following a color reaction with TMB, the absorbance at $450 \mathrm{~nm}$ was measured. The main working conditions were determined based on the above experiments.

The coated wells were further coated with $100 \mu$ l mouse anti-F1 IgG diluted in carbonate buffer ( $\mathrm{pH}$ 9.6) at $4{ }^{\circ} \mathrm{C}$ overnight. After washing three times with washing liquid (containing $0.5 \mathrm{ml} / 1$ Tween-220, pH 7.0, PBS solution, PBST), $100 \mu \mathrm{l}$ blocking solution (containing $10 \mathrm{mg} / \mathrm{ml} \mathrm{PBS}$ ) was added to each well at $37^{\circ} \mathrm{C}$ for $1 \mathrm{~h}$. After washing three times, $100 \mu \mathrm{l}$ of the samples was added to each well and incubated at $37^{\circ} \mathrm{C}$ for $1 \mathrm{~h}$. After another three washes, $100 \mu \mathrm{l}$ of mouse anti-HRSV IgG was added to each well and incubated at $37^{\circ} \mathrm{C}$ for $1 \mathrm{~h}$. After a further three washes, $50 \mu \mathrm{l}$ HRP rabbit anti-mouse IgG was added to each well and incubated at $37^{\circ} \mathrm{C}$ for $1 \mathrm{~h}$. After a final three washes, $50 \mu \mathrm{l}$ substrate solution (TMB) was added to each well and incubated at room temperature for $15 \mathrm{~min}$. Then $100 \mu \mathrm{l}$ sulfuric acid $(2 \mathrm{~mol} / \mathrm{l})$ was added to each well to terminate the reaction. The OD value at $450 \mathrm{~nm}$ was measured and the $\mathrm{S} / \mathrm{N}$ value was calculated using the following formula: $\mathrm{S} / \mathrm{N}$ = sample OD $450 \mathrm{~nm} /$ negative sample OD $450 \mathrm{~nm}$.

\section{Results}

Cloning and identification of the target gene. PCR products were detected using agarose gel electrophoresis. A specific 


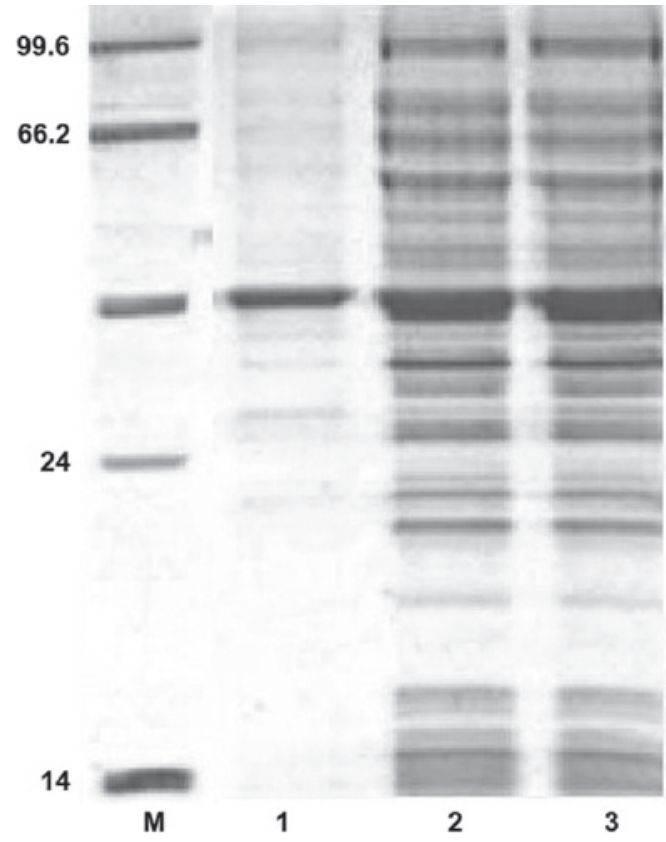

Figure 1. The SDS-PAGE results of the recombinant protein expression and purification. Lane M, low molecular weight protein marker; lane 1, purified recombinant protein; lane 2, precipitate of cell lysis; lane 3, supernatant of cell lysis.

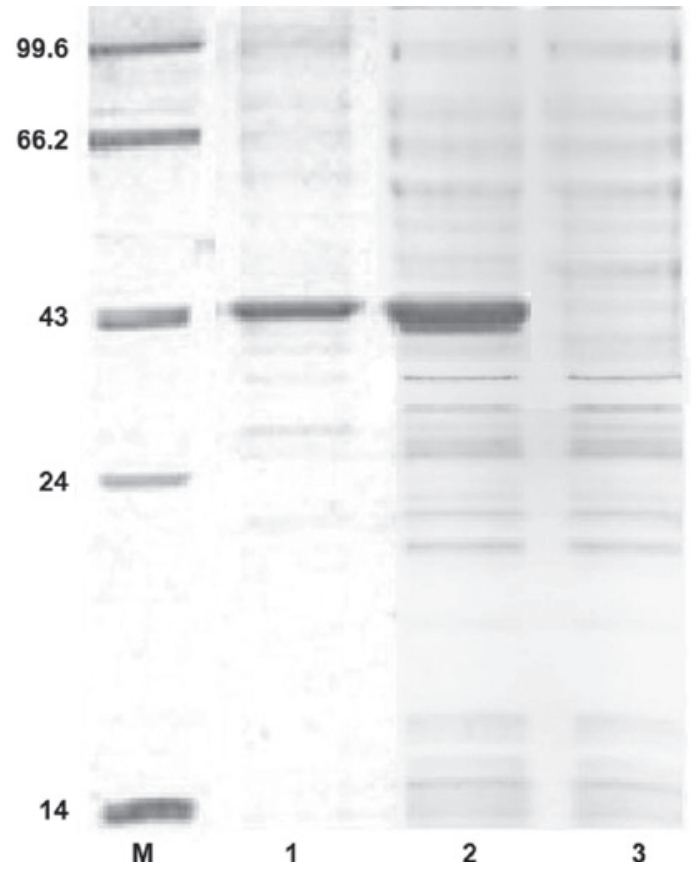

Figure 2. Western blot analysis results of the recombinant protein. Lane M, low molecular weight protein marker; lane 1, purified recombinant protein; lane 2 , total protein after cell lysis; lane 3 , total protein of pcDNA3.1 (+) blank vector after induction.

amplification band approximately 678 bp was observed. The HRSV F1 gene amplified by RT-PCR was purified and connected to the pGEM-T-easy vector to create the intermediate plasmid. The intermediate plasmid was digested by double digestion and the target gene fragment was retrieved. The target gene was connected with the pShuttle-CMV plasmid that was
Table I. Indirect sandwich ELISA test results of the clinical samples.

\begin{tabular}{lcccr}
\hline Sample & 1 & 2 & 3 & Mean \\
\hline Positive & 68 & 72 & 70 & 71 \\
\hline
\end{tabular}

ELISA, enzyme-linked immunosorbent assay; HRSV, human respiratory syncytial virus.

digested with the same double digestion, and the final connection was with the expression plasmid pcDNA3.1 (+). After the expression plasmid was digested by double restriction enzyme digestion, the gene fragment identified was $678 \mathrm{bp}$; consistent with the target gene. Sequencing results demonstrated that the inserted sequence was fully consistent with the target fragment.

Protein purification. The protein concentration before and after purification was quantified using a bicinchoninic acid assay (BCA), which was used to determine the recovery rate of the Ni-column purified F1-His protein. The total protein concentration before purification was $1,968 \mu \mathrm{g} / \mathrm{ml}$, and the total amount of protein was $398 \mu \mathrm{g}$. The concentration of the purified protein in the elution peak was $108 \mu \mathrm{g} / \mathrm{ml}$ and the total amount of protein was $58 \mu \mathrm{g}$. Therefore, the recovery rate of the F1-His protein was approximately $14.6 \%$. The purified protein was detected using SDS-PAGE, and the lysates of the COS27 cells transfected with the pcDNA3.1 (+) vector and pcDNA311 (+)/F1-His, respectively, were used as the control. The results demonstrated that there was a main band with a molecular weight of approximately 45,000 in lane 1 that was consistent with the expected size (Fig. 1).

Western blot analysis. After the induced protein was purified, it was analyzed using western blot analysis (Fig. 2). The results demonstrated that specific bands revealing antigen-antibody reaction appeared in the corresponding location, indicating that the expressed protein had a good immunogenicity response to its antibodies.

Establishment of indirect sandwich ELISA. The main working conditions were determined by the ELISA orthogonal test. The optimal concentration of mouse anti-F1 IgG was $3.2 \mu \mathrm{g} / \mathrm{ml}$, the optimal reaction time for the sample was $70 \mathrm{~min}$ at $37^{\circ} \mathrm{C}$, and the optimal working concentration of the rabbit anti-mouse IgG HRP was 1:6,000.

A total of 100 samples from the Changchun Children's Hospital were detected using the commercialized HRSV antibodies (IgG/IgM) gold testing kit, which revealed 66 positive cases of HRSV and 34 negative. A total of 20 negative samples were detected using the indirect sandwich ELISA at an OD value of $450 \mathrm{~nm}$. The positive threshold value was calculated according to the formula: positive threshold value $=$ mean of negative OD value $450 \mathrm{~nm}+3 \mathrm{x}$ standard deviation $=0.119+$ $0.015 \times 3=0.174$. Therefore, an OD value at $450 \mathrm{~nm}$ of 0.174 was used as the threshold value for judging the ELISA results. The results of 100 samples detected using indirect sandwich ELISA are shown in Table I. 
The results demonstrate that the difference of three t-test results between the indirect sandwich ELISA and the commercial kit were $0.114,0.08$ and 0.1000 , respectively, demonstrating no significant difference. In this study, it was revealed that, compared with the commercialized testing kit, the ELISA detection method established had the same detection capacity.

A total of 100 samples were analyzed with indirect ELISA, and each sample was repeated three times. The results demonstrated that the variation co-efficient of the positive samples was between 3.2 and $8.6 \%$, and the variation co-efficient of the negative sample was between 5.1 and $8.3 \%$. Both variation coefficients were $<10 \%$, therefore the method was reproducible.

\section{Discussion}

The HRSV F protein gene has less variation. Between the different subtypes, there is a highly homologous antigen, which is majorly cross-protective. There is also a large number of neutralizing antibody epitopes in the F protein. Studies have demonstrated that the antigenic sites II, IV, V, and VI are neutralizing epitopes, and are particularly conformational epitopes among the five known antigenic sites (I, II, IV, V, VI and II). Three subunit vaccines (PFP21, PFP22 and PFP23) created from the purified $F$ protein have recently entered clinical trials (5). The safety, immunogenicity and efficacy of the PFP23 vaccine have been confirmed for the protection of children with cystic fibrosis against HRSV lung infection. Treatment with the humanized monoclonal antibody, palivizumab, which targets the $\mathrm{F}$ protein has also achieved great success in the prevention of HRSV infection in high-risk groups $(6,7)$.

In this study, it was demonstrated that the antigen $F$ protein can be largely expressed in eukaryotic cells through transient transfection. The indirect sandwich ELISA method, which is based on the eukaryotic-expressed antigen had the same function as the commercial colloidal gold testing kit. At the present time, HRSV detection still relies on serum, and the colloidal gold is a high sensitivity method. The ELISA method has the advantage of being easy to perform and more environmentally friendly, in contrast to the high cost and more complex preparation process of the colloidal gold method. As the ELISA method is based on antigen protein expression in in eukaryotic cells, it has broad application prospects, but it is necessary to further research the efficiency of protein purification, experimental repeatability and stability.

In this study, the antigen protein was expressed after the PcDNA3.1 (+)/F1-His plasmid was transiently transfected into COS 27 cells. Western blot analysis demonstrated that F1-His fusion protein had the same immunogenicity as the F protein, and a molecular weight consistent with the expected value. The F1-His protein was purified using a Ni-column, and the purity and recovery rate met the requirements for monoclonal antibody preparation through immunized mice and the establishment of an indirect sandwich ELISA for diagnosis of HRSV infection. Since its establishment, the ELISA method has been widely used for the detection of various diseases, due to its easy operation, objectivity, sensitivity and other characteristics (8). The successful expression and purification of HRSV F protein-specific fragments in eukaryotic cells has laid a good foundation for an HRSV monoclonal antibody and immunological diagnostic research. The indirect ELISA test detection of the syncytial virus $\mathrm{F}$ protein was accurate and reliable, which provides a new rapid monitoring method for the prevention and control of respiratory syncytial virus infection.

\section{Acknowledgements}

This study was supported by a grant from the Science and Technology Department of Jilin Province (200705209).

\section{References}

1. Belino-Studzinska P and Pancer K: Respiratory syncytial virus: as an etiological agent of respiratory tract infection in children and adults. Przegl Epidemiol 62: 767-775, 2008 (In Polish).

2. Oshansky CM, Barber JP, Crabtree J and Tripp RA: Respiratory syncytial virus $\mathrm{F}$ and $\mathrm{G}$ proteins induce interleukin 1alpha, $\mathrm{CC}$, and CXC chemokine responses by normal human bronchoepithelial cells. J Infect Dis 201: 1201-1207, 2010.

3. Murata Y: Respiratory syncytial virus infection in adults. Curr Opin Pulm Med 14: 235-240, 2008.

4. Subbarayan P, Qin H, Pillai S, et al: Expression and characterization of a multivalent human respiratory syncytial virus protein. Mol Biol (Mosk) 44: 477-487, 2010.

5. Polack FP and Karron RA: The future of respiratory syncytial virus vaccine development. Pediatr Infect Dis J 23: S65-S73, 2004.

6. Collarini EJ, Lee FE, Foord O, et al: Potent high-affinity antibodies for treatment and prophylaxis of respiratory syncytial virus derived from B cells of infected patients. J Immunol 183: 6338-6345, 2009

7. Kohlmann R, Schwannecke S, Tippler B, et al: Protective efficacy and immunogenicity of an adenoviral vector vaccine encoding the codon-optimized $\mathrm{F}$ protein of respiratory syncytial virus. J Virol 83: 12601-12610, 2009.

8. Panadero R, Vazquez L, Colwell DD, et al: Evaluation of an antigen capture ELISA for the early diagnosis of Hypoderma lineatum in cattle under field conditions. Vet Parasitol 147: 297-302, 2007. 